The Structural Design of Tall and Special Buildings. (DOI: 10.1002/tal.693)

\title{
Numerical and Comparative Study of Earthquake Intensity Indices in Seismic Analysis
}

\author{
Lieping YE, Qianli MA, Zhiwei MIAO \\ Department of Civil Engineering, Tsinghua University, Beijing 100084, China \\ Hong GUAN* \\ Griffith School of Engineering, Griffith University Gold Coast Campus, Queensland 4222, Australia \\ Yan ZHUGE \\ Faculty of Engineering and Surveying, University of Southern Queensland, Queensland 4300, Australia
}

\begin{abstract}
Elastoplastic and time-dependent analysis of seismic structures has become a major analysis technique in popularly accepted performance-based seismic design. However the primary difficulty in using this technique is the lack of a unified criterion in the selection of various intensity indices of ground motions. Various earthquake factors influencing the elastoplastic response of seismic structures are highly sophisticating. Hence it is vitally important to choose an appropriate and comprehensive earthquake intensity index to achieve an accurate correlation with the structural performance. In this study, a total of 30 earthquake intensity indices published in the literature are reviewed and are evaluated through correlation analysis based on 60 ground motion records. Examined herein is the correlation between existing earthquake intensity indices and the seismic responses of elastoplastic SDOF and MDOF systems. The characteristics and applicability of such indices are also discussed in some detail, based on which appropriate earthquake intensity indices are recommended.
\end{abstract}

Keywords: Earthquake intensity index; SDOF and MDOF systems; correlation coefficient; seismic responses of structures.

\section{Introduction}

Time history analysis, being the most important analysis tool in performance-based seismic design, has become more and more popular worldwide. In the seismic design, seismic demand is mainly governed by three factors namely the peak value of ground motion, the characteristic of earthquake spectrum and duration. An earthquake intensity index of ground motions is normally used as a scaling parameter which is critical for seismic analysis and design. A number of researchers (Fajfar el al. 1990; Housner and Jennings 1977; Riddell and Garcia 2001; Nau and Hall 1984; Hao et al. 2005; Sucuoglu and Nurtug 1995; Arias 1970; Trifunac and Brady 1975) have, from their own perspective, proposed various intensity indices. However due to the complexity and randomness of earthquake motion, it has been a difficult task to accurately evaluate the applicability of various existing intensity indices. In addition, an objective and quantitative method is lacking in the evaluation of the applicability of such indices. This has been a challenging issue in seismic engineering research and has become a fundamental problem in performance-based seismic design.

An extensive study on earthquake intensities has been conducted which can be classified into

${ }^{*}$ Corresponding author. Tel: +61-7-5552 8708

E-mail address: h.guan@griffith.edu.au 
two major categories (Liu 1958): (1) intensities in relation to the ground motion parameters which are directly obtained from ground motion records, such as Peak Ground Acceleration (PGA) and Peak Ground Velocity (PGV); (2) intensities in relation to the structural seismic response spectrum, such as Peak Spectrum Acceleration (PSA) and Peak Spectrum Velocity (PSV). Traditionally, the most widely accepted intensity index for seismic structural analysis is PGA which is also used in most national building codes such as Eurocode8 (1994) and China GB50011-2001 (2001). This is due to a historical reason as PGA is the most simple and easy-to-use index and is most suited for short-period structures. Moreover, in the early days of introducing seismic design procedures, most building structures were of low-rise with short fundamental period. This facilitated the use of PGA as a popular intensity index. However with technological development, the building height increases remarkably and the breath and depth of seismic research has also advanced considerably. Under these circumstances, the limitation of the application scope of PGA becomes more obvious. Fajfar et al.'s (1990) study indicated that there is increasing evidence that PGA is a poor measure of the damage potential of earthquake ground motions. This is further supported by Housner and Jennings (1977) who concluded that it is inherently impossible to describe the complex earthquake phenomenon by a single measure by which the complicated earthquake characteristics cannot be fully described. In view of this, a three-parameter intensity index was introduced capable of providing different intensity measures for short- to long-period regions (Riddell and Garcia 2001). Despite its wide coverage, the development of a multi-parameter index was considered too complicated for practical application. This has been verified by Nau and Hall (Nau and Hall 1984) who concluded that no matter what format an intensity index (scaling parameter) has, the key constituent elements are the peak motions from the ground motion data. As a potential alternative, Fajfar et al. (1990) indicated that the spectrum intensities may also be used as a scaling parameter for seismic analysis.

In seismic analysis, the primary concern is that whether a unified and effective relationship exists between the intensity index and the actual structural damage, thereby the seismic performance can be objectively and accurately evaluated. As a matter of fact, earthquake damage capacity can be reflected by the degree of structural damage, which is in turn determined by the structural responses including maximum deformation and plastic hysteresis energy dissipation (Fajfar el al. 1990). In view of this, the said responses under a given ground motion can be used to evaluate the corresponding seismic intensity which is quantified by the intensity index. In analyzing structural hysteresis energy spectrums, Riddell and Garcia (Riddell and Garcia 2001) investigated the applicability of a number of various intensity indices through statistical analyses of three representative single degree-of-freedom (SDOF) systems with different structural periods. Using the concept of an average coefficient of variation $(\overline{C O V})$, the correlation relationship between the seismic hysteresis energy dissipation and the intensity indices was quantitatively examined, by which the applicability of the indices can be determined. Despite the complexity of Riddell and Garcia's concept in using $\overline{C O V}$, their methodology in establishing a correlation relationship is noteworthy. The work has been further advanced recently by the same author (Riddell 2007) to cover the four response variables: elastic and inelastic deformation demands, and input energy and hysteretic energy. It should be recognised however that existing research is limited to SDOF systems. It is therefore necessary to conduct a more comprehensive study to cover a full range of structural configurations including SDOF and MDOF (multi degree-of-freedom) systems. 
In this study, a number of existing intensity indices are reviewed and summarized. They include those in relation to the earthquake ground motions as well as those associated with the structural responses. A correlation coefficient is calculated to evaluate the correlation between existing earthquake intensity indices and the seismic responses of elastoplastic SDOF and MDOF systems. The characteristics and applicability of such indices are also discussed in some detail, based on which an appropriate earthquake intensity index is recommended.

\section{Existing Earthquake Intensity Indices}

\subsection{Peak Ground Acceleration (PGA)}

For seismic structural analysis purposes, the most simple and widely used intensity index is PGA which is also adopted in many structural design codes or provisions worldwide. Although PGA is an important intensity index, its scope of application is limited because a single measure is unable to fully describe the complex earthquake characteristics. Nevertheless PGA is still widely used due to its convenience and simplicity. According to previous research (Hao et al. 2005), the Peak Ground Velocity (PGV) can better reflect the damage intensity level than PGA. In the Japanese building code (2000), PGV is used as an index in seismic analysis and the values of PGV corresponding to different earthquake hazards are prescribed. Less popularly used index is the Peak Ground Displacement (PGD) which has been compared to other indices in the study of Riddell and Garcia (2001).

\subsection{Ratio of Peak Ground Velocity and Peak Ground Acceleration (PGV/PGA)}

For certain ground motions the PGA and PGV, induced by different spectrum components, exhibit different attenuations. To take into account the effects of both PGA and PGV, the ratio of PGV and PGA, i.e. PGV/PGA was thus considered to be an intensity index (Sucuoglu and Nurtug 1995; Vamvatsikos and Cornell 2002).

\subsection{Housner Spectrum Intensity}

As suggested by Housner (1952), the relationship between the maximum strain energy $E_{\mathrm{e}, \max }$ stored in a seismic elastic system and its pseudo-velocity response $S_{\mathrm{v}}$ is

$$
E_{\mathrm{e}, \max }=m S_{\mathrm{v}}^{2} / 2
$$

which indicates that the pseudo-velocity spectrum itself can be used to measure the severity of earthquakes in seismic analysis. It can also be used to evaluate the earthquake input energy and damage capacity to structures. Housner (1952) further defined the spectrum intensity as:

$$
S_{\mathrm{I}}(\xi)=\int_{0.1}^{2.5} S_{\mathrm{v}}(\xi, T) \mathrm{d} T
$$

where the time integral refers to the area under the pseudo-velocity response spectrum $S_{\mathrm{v}}$ over the period range $T$ of 0.1 to $2.5 \mathrm{~s}, \xi$ is the damping ratio of a structure.

\subsection{Arias Intensity}

Considering the total dissipation energy per unit mass of an elasto-plastic system, Arias (1970) proposed an intensity parameter applicable to structures with all natural frequencies: 


$$
I_{\mathrm{A}}(\xi)=\frac{\cos ^{-1} \xi}{g \sqrt{1-\xi^{2}}} \int_{0}^{t_{\mathrm{f}}} \ddot{x}^{2}(t) \mathrm{d} t
$$

where $I_{\mathrm{A}}$ is called Arias intensity, $\xi$ is the damping ratio of a structure, $g$ is the gravity acceleration, $t_{\mathrm{f}}$ is the total duration of ground motion and $\ddot{x}(t)$ is the time history of ground acceleration. Based on Arias intensity, Trifunac and Brady (1975) defined a significant duration of ground motion as

$$
t_{\mathrm{D}}=t_{95}-t_{5}
$$

where $t_{95}$ and $t_{5}$ are respectively the times where $95 \%$ and $5 \%$ of Arias intensity is reached (Equation (3)). The significant duration as defined in Equation (4) is to-date most widely used for evaluating the effective durations of earthquakes.

\subsection{Modified Arias Intensity}

Araya and Saragoni's study (1984) demonstrated that although Arias Intensity is able to reflect the peak motion and duration of earthquake, it does not replicate frequency characteristics of ground motions. Therefore, a modified Arias intensity considering frequency characteristics was proposed. Or,

$$
P_{\mathrm{D}}=I_{\mathrm{A}} / v_{0}^{2}
$$

where $I_{\mathrm{A}}$ is Arias intensity given in Equation (3) and $v_{0}$ is the number of zero-crossings per unit time on the accelerogram.

\subsection{Housner Intensity}

As suggested by Housner (1975), the capacity of ground motion to damage structures can be estimated by the average rate of total seismic input energy per unit mass during the quake motion. Based on the fact that the total input energy is directly proportional to the time integral of a squared ground acceleration, an intensity index was then proposed as follows:

$$
P=\frac{1}{t_{2}-t_{1}} \int_{t_{1}}^{t_{2}} \ddot{x}^{2}(t) \mathrm{d} t
$$

where $t_{1}$ and $t_{2}$ are the limits of the strong portion of ground motion. Mathematically, Equation (6) implies that the index is an average value of the squared acceleration over the interval between $t_{1}$ and $t_{2}$. Substituting the limits $t_{95}$ and $t_{5}$ of significant duration $t_{\mathrm{D}}$ into Equation (6), the index $P$ is then presented by the mean-square acceleration $P_{a}$ as follows

$$
P_{a}=\frac{1}{t_{\mathrm{D}}} \int_{t_{5}}^{t_{55}} \ddot{x}^{2}(t) \mathrm{d} t
$$

Similarly, the mean-square velocity $P_{\mathrm{v}}$ and the mean-square displacement $P_{\mathrm{D}}$ can be defined as

$$
\begin{aligned}
& P_{\mathrm{v}}=\frac{1}{t_{\mathrm{D}}} \int_{t_{5}}^{t_{95}} \dot{x}^{2}(t) \mathrm{d} t \\
& P_{\mathrm{d}}=\frac{1}{t_{\mathrm{D}}} \int_{t_{5}}^{t_{95}} x^{2}(t) \mathrm{d} t
\end{aligned}
$$


where $\dot{x}(t)$ and $x(t)$ are the ground velocity and displacement histories, respectively. The corresponding root forms of $P_{\mathrm{a}}, P_{\mathrm{v}}$ and $P_{\mathrm{D}}$, referred to as the root-mean-square motions (Housner and Jennings 1964), are given below

$$
\left\{\begin{array}{l}
a_{\mathrm{rms}}=\sqrt{P_{a}} \\
v_{\mathrm{rms}}=\sqrt{P_{\mathrm{v}}} \\
d_{\mathrm{rms}}=\sqrt{P_{\mathrm{d}}}
\end{array}\right.
$$

\subsection{Nau and Hall Indices}

For simplicity, Nau and Hall (1982) proposed the time integrals of the squared ground motions as the intensity indices without including the damping ratio and gravity acceleration as used in Arias intensity, as follows:

$$
\left\{\begin{array}{l}
E_{a}=\int_{0}^{t_{\mathrm{f}}} \ddot{x}^{2}(t) \mathrm{d} t \\
E_{\mathrm{v}}=\int_{0}^{t_{\mathrm{f}}} \dot{x}^{2}(t) \mathrm{d} t \\
E_{\mathrm{d}}=\int_{0}^{t_{\mathrm{f}}} x^{2}(t) \mathrm{d} t
\end{array}\right.
$$

where $t_{\mathrm{f}}$ is the total duration of the ground motion. Similarly, the root forms of Nau and Hall indices are given below

$$
\left\{\begin{array}{l}
a_{\mathrm{rs}}=\sqrt{E_{a}} \\
v_{\mathrm{rs}}=\sqrt{E_{\mathrm{v}}} \\
d_{\mathrm{rs}}=\sqrt{E_{\mathrm{d}}}
\end{array}\right.
$$

\subsection{Park-Ang Intensity}

Park et al. (1985) proposed an index named "characteristic intensity" given by

$$
I_{\mathrm{C}}=a_{\mathrm{rms}}^{1.5} t_{\mathrm{D}}^{0.5}
$$

where $a_{\mathrm{rms}}$ is defined in Equation (10) and $t_{\mathrm{D}}$ is the significant duration. The proposed intensity index has proven to correlate well with structural damage and can be considered a reasonable representation of the destructive ground motions.

\subsection{Fajfar Intensity}

Fajfar et al. (1990) proposed a measure of the ground motion capacity to damage structures with their fundamental periods in the intermediate period range as follows:

$$
I_{\mathrm{F}}=v_{\max } t_{\mathrm{D}}^{0.25}
$$

where $v_{\max }$ is the peak ground velocity and $t_{\mathrm{D}}$ is the significant duration of ground motions.

\subsection{Riddell's Three-Parameter Intensity}

Based on the intensity indices previously developed by other researchers, Riddell and Garcia 
(2001) proposed a new generalized intensity index formula in the form of

$$
I=Q^{\alpha} t_{\mathrm{D}}^{\beta}
$$

where $Q$ is the governing intensity indices for different spectral regions, $\alpha$ and $\beta$ are constants that can be determined by the optimization procedure. Based on a statistical analysis, the following indices were recommended to predict hysteresis energy dissipation during earthquakes:

$$
\begin{aligned}
& I_{\mathrm{d}}=d_{\text {max }} t_{\mathrm{D}}^{1 / 3} \\
& I_{\mathrm{v}}=v_{\text {max }}^{2 / 3} t_{\mathrm{D}}^{1 / 3} \\
& I_{a}=\left\{\begin{array}{l}
a_{\max } t_{\mathrm{D}}^{1 / 3} \\
a_{\max }
\end{array}\right.
\end{aligned}
$$

where $I_{\mathrm{d}}$ and $I_{\mathrm{v}}$ are applicable to the displacement and velocity regions, respectively, of the spectrum for any load-deformation model. $I_{a}$ is used for the acceleration region, with Equation (16c-1) for stiffness deterioration models and Equation (16c-2) for elastoplastic or bilinear systems.

\subsection{1. "First-Mode” Spectral Acceleration}

According to Bazzurro et al.'s (1998) study, seismic response of a first-mode dominated structure is sensitive to the strength of the frequency content near its first-mode frequency. Therefore, the first-mode spectral acceleration $S_{\mathrm{a}}\left(T_{1}\right)$ was proposed as an intensity index. The major advantages of this index lie in its simplicity and a relatively smaller dispersion in predicting the seismic responses (Vamvatsikos and Cornell 2002). However due to the use of the first-mode spectral acceleration, this index may not produce ideal solutions for tall and long-period structures having higher vibration modes.

\subsection{Cumulative Absolute Velocity (CAV)}

The Cumulative Absolute Velocity (CAV) was originally developed for applications in Nuclear Power Industry (Kramer 1996). CAV is defined as the integral of the absolute value of ground acceleration over the seismic time-history record. The CAV value correlates highly with physical property damage.

The CAV has been recommended by Kramer (1996) as an alternative intensity index which can be expressed as

$$
\mathrm{CAV}=\int_{0}^{t_{\mathrm{f}}}|\ddot{x}(t)| \mathrm{d} t
$$

where $t_{\mathrm{f}}$ and $\ddot{x}(t)$ are as previously defined.

\subsection{Effective Design Acceleration}

Benjamin and Associates (1988) found that high frequency components of ground motions have little effect on the seismic responses of structures. However the influence on the peak ground acceleration is remarkable. Therefore, a scaling parameter using the peak acceleration value was proposed. It was determined upon low-pass filtering of the input time history with a 
cut-off frequency of 9Hz. It is also called Effective Design Acceleration (EDA).

\subsection{Summary of Intensity Indices}

In addition to the abovementioned indices, many other intensity parameters are also available. For example, Sustained Maximum Acceleration (SMA) and Sustained Maximum Velocity (SMV) as proposed by Nuttli (1979). The SMA and SMV are respectively the third maximum acceleration and velocity measured over the time history. Another parameter proposed by Sarma and Yang (1987) is A95 which is the maximum value of acceleration that corresponds to $95 \%$ of the Arias Intensity value. Being less popular, these indices are not included in the present comparative study. Those that are detailed in Sections 2.1 to 2.14 are used to evaluate their correlation with the seismic responses of elastoplastic SDOF and MDOF systems. They are also summarized in Table 1 which amounts to a total of 30 indices.

It should be noted that it is barely possible to describe the complex earthquake phenomenon by a single measure. In engineering practice, a simple and rational earthquake intensity index that can describe the damage capacity of a structure is highly desirable. Indices with a single parameter or in simply combined expressions are still popular in seismic analysis because of their simplicity. Based on numerical analyses, Riddell and Garcia (2001) stated that certain intensity indices are suitable for specified spectral regions. Intensities in terms of PGA are most suitable for the acceleration (short period) region, and those in terms of PGV are most appropriate for the velocity (intermediate period) region and PGD, for the displacement region (long period). This further suggests that none of the existing indices with a single parameter or in simply combined expressions performs the best for the entire range of natural frequencies. As discussed in Section 2.11, the multi-parameter intensity indices work relatively better in most range of structural period. However, as a scaling parameter, the multi-parameter indices have shown to be complex and imperfect for all frequencies as discussed later. Therefore, the best solution is to select the most appropriate intensity indices for individual cases.

Note also that in the present comparative study, each of the three-parameter intensity indices as proposed by Riddell and Garcia (2001) is evaluated for all frequency ranges. The solutions are then combined for further evaluation. Further, the second expression in index $I_{a}$ is equivalent to PGA. Thus only the first expression is considered in the analysis.

\section{Earthquake Records}

A group of sixty (60) accelerograms are selected from PEER database (2005) as listed in Table 2, with PGA between $0.089 \mathrm{~g}$ and $0.822 \mathrm{~g}$, PGV between $4.0 \mathrm{~cm} / \mathrm{s}$ and $89.66 \mathrm{~cm} / \mathrm{s}$, and PGD between $0.17 \mathrm{~cm}$ and $57.01 \mathrm{~cm}$. The significant duration $t_{\mathrm{D}}$ is in the range of $1.83 \mathrm{~s}$ to $36.62 \mathrm{~s}$. It should be stated that most of the earthquake records selected for this study represent small to moderate intensities of motion where the peak ground accelerations are around 0.2 to $0.4 \mathrm{~g}$. Due to lack of data, some important geotechnical information such as site effects, tectonic environment, near field effects and distance to fault are not considered. Furthermore, to achieve more accurate results, earthquake records with similar characteristics should also be classified into different categories so as to reduce the number of scattered points in the results. 


\section{Evaluation Procedure for Intensity Index Comparison}

Presented in Section 2 are existing intensity indices proposed by different researchers to describe the capacity of various ground motions to damaged structures. Research on a comprehensive evaluation of all these indices is very limited (Riddell 2007), in particular their applicability for different structures in seismic analysis. The most appropriate intensity index should be able to reflect the seismic response or damage of building structures, with particular emphasise of its simplicity. The analysis is performed on a series elastoplastic SDOF and MDOF systems. The detailed evaluation procedure is summarized as follows:

(1) Consider one of the seismic responses and name it as Rep. Based on an elastoplastic SDOF or MDOF system with fundamental period $T$, the maximum response $\operatorname{Rep}_{i}$ of the system under the $i$ th ground motion is calculated by time history analysis;

(2) For a specific intensity index $I$, the value of $I$ under the $i$ th ground motion from the selected earthquake records can be obtained, which is marked as $I_{i}$;

(3) Repeat Steps (1) and (2), and record all the results of $I_{i}$ and the corresponding $\operatorname{Rep}_{i}$, until the entire group of ground motions are covered (a total of 60 records in this study);

(4) Plot all the 60 results obtained in Step (3) on a Rep-I coordinate system as illustrated in Figure 1. Also given in the figure is the linear regression of the results when the intercept is set to be zero. Using a statistical method, the correlation coefficient $\rho$ of the $60\left(\operatorname{Rep}_{i}, I_{i}\right)$ points for fundamental period $T$ can be calculated;

(5) Change the structural fundamental period $T$, repeat Steps (1) to (4). The new correlation coefficient obtained for the modified $T$ is plotted on the $\rho$ - $T$ coordinate system. This exercise is repeated for a number of different fundamental periods for various systems concerned;

(6) Consider a different seismic response Rep and a different intensity index $I$, repeat Steps (1) to (5) to obtain a series of $\rho$ - $T$ relationships;

(7) For a specific seismic response Rep, the applicability of different index $I$ in different frequency regions can be estimated by comparing the relative values of correlation coefficients. If the coefficient is relatively high in a certain frequency region, it implies that the corresponding index $I$ is comparatively better for the specific seismic response analysis. Otherwise, $I$ is considered insufficiently suitable. For different seismic responses with various structural characteristics, the applicability of all the indices can be evaluated by which the most appropriate intensity index can be determined.

\section{Analysis of SDOF systems}

\subsection{System details}

A series of simple spring-mass SDOF systems (5\% of critical damping) are analyzed, of which the strength reduction factor $R$ is set to be 1 for elastic and 2, 3, 4, 6 and 8 for elasto-plastic systems. The fundamental periods are taken from $0.1 \mathrm{~s}$ to $6 \mathrm{~s}$ at a $0.1 \mathrm{~s}$ interval. Illustrated in Figure 2 is the simplified bilinear load-deformation hysteresis models used in the analysis. The coefficient of post-yield stiffness $\alpha$ for all the cases is assumed to be constant as 0.1 . For any specific seismic response and any specific intensity index (for any one figure in Figures 3 and 4), a total of 360 SDOF systems are studied and 21600 ground motion cases are calculated. 


\subsection{Analysis results}

All the maximum seismic responses of the SDOF systems are calculated including displacement $\left(S_{\mathrm{d}}\right)$, base shear (equivalent to spectral acceleration, $S_{\mathrm{a}}$ ), input energy $\left(E_{\mathrm{I}}\right)$ and hysteresis energy $\left(E_{\mathrm{H}}\right)$. Being the most critical parameters for performance-based design, the maximum structural displacement $S_{\mathrm{d}}$ and the input energy $E_{\mathrm{I}}$ of the systems for typical intensity indices $I$ are illustrated in Figures 3 and 4 respectively. Not included are those exhibiting similar behavior. Note that for both $S_{\mathrm{d}}$ and $E_{\mathrm{I}}$, the general trend of correlation variations is similar for any specific index $I$ under the variation of strength reduction factor $R$ (elastic and elasto-plastic). Note also that for any specific index $I$, the correlation coefficient $\rho$ is different in terms of $S_{\mathrm{d}}$ and $E_{\mathrm{I}}$ for different structures (having different period $T$ and strength reduction factor $R$ ).

For further discussion, the $\rho-T$ relationships presented in Figures 3 and 4 can be approximately classified into three groups based on the intensity index $I$.

\section{Group 1}

The first group of $I$ are represented by PGA, which includes PGA, $I_{\mathrm{A}}, P_{a}, a_{\mathrm{rms}}, E_{a}, a_{\mathrm{rs}}, I_{\mathrm{c}}, I_{a}$ and EDA (Figures 3(a), 4(a)). The $\rho-T$ relationships for $S_{\mathrm{d}}$ (Figure 3) show that the correlation coefficient $\rho$ generally decreases with an increase in the structural period $T$ with a few local oscillations. Similar relationships are found for $E_{\mathrm{I}}$ (Figure 4) with a slightly increased $\rho$ for long-period systems than the intermediate-period counterparts. Structures with short period are within the acceleration region. Hence the acceleration-related intensity indices $I$ grouped herein demonstrate a high correlation with the maximum seismic responses in the short period.

\section{Group 2}

The second group of $I$ are represented by PGV, including PGV, PSV, $S_{\mathrm{I}}, I_{\mathrm{A}, \mathrm{m}}, P_{\mathrm{v}}, v_{\mathrm{rms}}, v_{\mathrm{rs}}, I_{\mathrm{F}}, I_{\mathrm{v}}$ and CAV (Figures 3(b), 4(b)). For elastic systems $(R=1)$, the correlation coefficients are low for short-period structures and remains relatively stable for intermediate-period ones. For long period structures, the correlations are reduced for both $S_{\mathrm{d}}$ and $E_{\mathrm{I}}$. For elastoplastic systems $(R>1)$, the correlations for all frequency ranges are relatively higher and more stable than those of the elastic systems, especially in the intermediate period range. For $S_{\mathrm{d}}$, little difference is resulted for different $R$. This is however not the case for $E_{\mathrm{I}}$ where higher $R$ yields better correlation. Structures with intermediate period are within the velocity region. This results in a high correlation between the velocity-related indices with the maximum seismic responses in the intermediate period.

Also included in this group is index $S_{a}\left(T_{1}\right)$ which is spectrum related. Similar to other indices in this group, $S_{a}\left(T_{1}\right)$ performs excellent in the entire range of structural period for an elastic system. This is also the case for elastoplastic systems except that the correlations are relatively low in short period range. For seismic analysis purpose, $S_{a}\left(T_{1}\right)$ is considered a better choice for intermediate- to long-period structures.

\section{Group 3}

The third group of $I$ is represented by the displacement-related indices including PGD, PSD, $P_{\mathrm{d}}, d_{\mathrm{rms}}, E_{\mathrm{d}}, d_{\mathrm{rs}}$ and $I_{\mathrm{d}}$ (Figures $3(\mathrm{c}), 4(\mathrm{c})$ ). For the long period range (approximately $>2 \mathrm{~s}$ ), a high correlation is achieved; otherwise the correlation is considerably lowered with a reduction in structural period. The high correlation in the long-period range corresponds to the fact that the 
behavior of long-period structures is governed by the peak displacement. Also included in this group are $\mathrm{PGV} / \mathrm{PGA}$ and $E_{\mathrm{v}}$ which are indirectly related to the peak displacement. This is because their resulting correlations are similar to those of other indices grouped herein.

As previously mentioned, each of Riddell and Garcia's (2001) three-parameter intensity indices $\left(I_{a}, I_{v}\right.$ and $\left.I_{d}\right)$ is evaluated individually for all frequency ranges (Figures 3(a), (b), (c)). It is noticed that these three parameters fall within three different groups. When combining the three sets of $\rho-T$ relationships as indicated in Figure 5, Riddell's indices are shown to be advantageous than others in that a good correlation can always be achieved for various structural period regions by using one of the three parameters. Such an advantage, however, is lessened by the cumbersome application in practice because no clear distinction of structural period regions is available for a corresponding and applicable index.

\subsection{Discussion on intensity indices based on SDOF systems}

PGA is the most widely and easily used intensity index. PGA and other acceleration-related indices (Group 1) have shown to produce very poor correlations in the intermediate and long structural period ranges which can hardly reflect the influence of ground motions on intermediateand long-period structures. Hence indices in Group 1 are more suitable for structures with short period. Indices in Group 3, on the other hand, are mostly suitde for structures with long period and not recommended for use in short-period structures. Compared to indices in Groups 1 and 3 which have limited applicability, Group 2 indices have demonstrated to produce the best correlation for a wider range of structural period except for very short-period structures.

A further discussion then follows with particular emphasise of the indices in Group 2 where the $\rho-T$ relationships are plotted for all the maximum seismic responses, viz acceleration $S_{\text {a }}$, displacement $S_{\mathrm{d}}$, input energy $E_{\mathrm{I}}$ and hysteresis energy $E_{\mathrm{H}}$. They are presented in Figure 6 showing the correlations of each index in Group 2 with the structural seismic responses. A fixed value of $R(=4)$ is chosen to represent a popularly used structure having elasto-plastic behaviour. Figures 6(a) and (b) further demonstrate that most velocity-related indices correlate well with $S_{\mathrm{a}}$ and $S_{\mathrm{d}}$ for a wider range of structural period. For $E_{\mathrm{I}}$ and $E_{\mathrm{H}}$ (Figures 6(c) and (d)), the correlation coefficients for all the indices are fairly similar for structures with intermediate period. However these coefficients obviously differ especially for very short or long-period structures. Nevertheless the correlations with respect to the energy responses are considered sufficiently high which is well suited for seismic analysis.

Based on the above discussions, it is suggested herein that the velocity-related intensity indices in particular PGV is most applicable for structures with intermediate periods due to its simplicity. Moreover, intensity index $S_{a}\left(T_{1}\right)$, covering an entire range of structural period, is also proven to be a well-suited index for typical structures (fundamental period longer than $0.4 \mathrm{~s}$ ). A direct relation to the design spectrums also makes $S_{a}\left(T_{1}\right)$ more practically appealing. For structures with less than $0.4 \mathrm{~s}$ period, however, PGA can be a better alternative.

\section{Analysis of MDOF systems}

The correlations between the intensity indices and structural seismic responses have been 
evaluated through elastoplastic SDOF systems, which can only represent structures dominated by the first or fundamental frequency. For most practical structures in particular high-rise buildings which are largely influenced by higher order vibration modes, MDOF systems are needed to examine much more sophisticated seismic responses that cannot be adequately described by SDOF systems.

\subsection{System details}

In this study, two different MDOF systems are studied viz the lumped mass shear story models as illustrated in Figure 7 and the planar frame shear-wall structures as shown in Figure 8. In the lumped mass shear story models, the mass and stiffness of each story are 600 Ton and $10^{9} \mathrm{~N} / \mathrm{m}$, respectively. The relationship between the story shear and drift is illustrated in Figure 7(b). A total of 10 lumped mass models are analyzed with respectively 3, 6, 8, 10, 12, 15, 20, 30, 40 and 50 stories. The corresponding fundamental periods are $0.29 \mathrm{~s}, 0.59 \mathrm{~s}, 0.78 \mathrm{~s}, 0.98 \mathrm{~s}, 1.17 \mathrm{~s}$, $1.47 \mathrm{~s}, 1.96 \mathrm{~s}, 2.94 \mathrm{~s}, 3.92 \mathrm{~s}$ and $4.90 \mathrm{~s}$, respectively. The yield story drift is $1 / 250$ and the coefficient of post-yield stiffness is 0.1 . The second MDOF systems consist of five frame shear-wall structures with 8,12,18, 24 and 30 stories. The corresponding fundamental periods are 0.46s, $0.76 \mathrm{~s}, 1.29 \mathrm{~s}, 1.93 \mathrm{~s}$ and $2.73 \mathrm{~s}$, respectively. All the MDOF models have 5\% Rayleigh damping. For any specific seismic response and any specific intensity index, a total of 15 MDOF systems are studied and 900 ground motion cases are calculated.

Each of the frame shear-wall structures is idealized as frame and shear wall which are hinge connected by rigid links at story levels, as illustrated in Figure 8. The frame (beams and columns) is simulated using fiber-model elements (Ye et al. 2006) as shown in Figure 9(a). Each fiber element representing concrete and steel reinforcement is subdivided into a number of longitudinal fibers having uniaxial behavior. The compatibility of each fiber is achieved by plane section assumption. The fiber element allows definition of position, cross-sectional area and constitutive relationships of each fiber. It can be used to simulate members with various cross-sections. For slender members in particular, the interrelationship between the axial force and uniaxial/biaxial moment can be accurately described.

The shear wall is modeled using the so-called multilayer shell elements (Ye et al. 2006) as presented in Figure 9(b). In the model, each element is subdivided into a number of layers over its thickness direction. Each layer has its own thickness and material properties which can represent concrete and steel. In the analysis, the strain field of each layer can be obtained by the mid-layer strain and curvature, complying with the plane section assumption. The corresponding stresses in each layer can then be obtained using material constitutive relationships. Finally the internal forces in each element can be calculated through numerical integration. The use of multilayer shell elements is able to relate the constitutive relation of concrete and steel to the nonlinear behavior of shear wall structures. The element can also be used to solve coupling problems associated with in-plane bending and shear as well as out-of-plane bending. This makes it a more superior model over others in analyzing complex nonlinear behavior of shear wall structures. The numerical analysis of frame shear-wall structures is performed using MSC.MARC. 


\subsection{Analysis results and discussion on intensity indices based on MDOF systems}

For nine typical intensity indices, the $\rho$-T relationships are demonstrated in Figsure 10 and 11 respectively for the lumped mass and frame shear-wall systems. Included in these figures are the structural seismic responses including the peak roof displacement, the maximum story drift, the maximum base shear and the total input energy. These results are used to supplement the findings obtained from the SDOF systems.

For the lumped mass MDOF systems, the $\rho-T$ relationships for the peak roof displacement (Figure 10(a)), the maximum story drift (Figure10 (b)) and the input energy (Figure10 (d)) demonstrate a similar variation of the correlation coefficient with an increase in period. It is noted that the three indices in Group 1 give a relatively high correlation for short period, whereas the correlation is low for medium to long period. It is generally vice versa for the two indices in Group 3. The four indices in Group 2 perform the best for medium period, but the correlation is relatively low for short and long period. These findings are similar to those obtained from the SDOF systems and from Riddell (2007). Unlike the abovementioned responses, the maximum base shear results (Figure10 (c)) show that the best correlation for short period is achieved by $S_{\mathrm{a}}\left(T_{1}\right)$ which is followed by indices in Group 1 and remaining ones in Group 2. Those in Group 3 still produce lowest correlation. For medium and long period, the correlation due to $S_{\mathrm{a}}\left(T_{1}\right)$ lowers with increase in period while other indices produce better correlation.

For planar frame shear-wall structures, the over $\rho$-T relationships (Figure 11) are similar to those of the lumped mass MDOF systems with an exception of less oscillation for any specific index. This is due to the fact that very short period is excluded in the analysis.

Following the early discussion based on SDOF systems, Group 2 indices are best suited for a wide range of structural period except for the very short-period structures, this is due to the fact that the structural period of MDOF systems is normally within the range of intermediate period. Hence Group 2 indices represented by PGV demonstrate a higher correlation. As far as intensity index $S_{\mathrm{a}}\left(T_{1}\right)$ is concerned, the lumped mass systems show a good correlation with the peak roof displacement, the maximum story drift and the total input energy. However the correlation is relatively poor with the maximum base shear of the building. This is also found for the frame shear-wall structures. Therefore, the index $S_{\mathrm{a}}\left(T_{1}\right)$ should not be used if the base shear responses of buildings are the primary concern of the design and analysis.

\section{Conclusions}

Based on a comprehensive analysis of elastoplastic SDOF and MDOF systems, the correlations between the existing intensity indices and major seismic responses of structures are studied confirming some of the well-accepted deductions and leading to several recommendations:

Classified into three categories, the first group of intensity indices represented by PGA has a high correlation in the short period range but a poor correlation in the intermediate and long period ranges; the second group represented by PGV has a sufficient correlation for seismic analysis purpose in intermediate and some long period regions; and the third group represented 
by PGD has a high correlation in long period range only.

The most widely used intensity PGA is shown less suited for performance-based design or estimation. The intensity PGV, on the other hand, gives relatively high correlations between intensity and seismic responses in intermediate and some long period regions. With sufficient simplicity, PGV may be a better intensity index for performance-based seismic analysis and design except for very rigid systems with high frequency. The intensity $S_{\mathrm{a}}\left(T_{1}\right)$ has a good correlation with the structural top displacement, maximum story drift and total input energy of structures even if the structural fundamental periods are relatively long. It however shows a poor correlation with the maximum base shear when applied to MDOF systems. In view of this, the intensity $S_{\mathrm{a}}\left(T_{1}\right)$ is not suitable for MDOF systems although it is in general a good index for seismic analysis.

\section{References:}

Araya R, Saragoni R. 1984. Earthquake accelerogram destructiveness potential factor. Proceedings of the 8th World Conference of Earthquake Engineering, San Francisco, USA. vol. 2: 835-841.

Arias A. 1970. A measure of earthquake intensity. Seismic Design for Nuclear Power Plants. Hansen RJ (Ed.), MIT Press, Cambridge: 438-483.

Bazzurro P, Shome N, Cornell CA, Carballo JE. 1998. Three proposals for characterizing MDOF non-linear seismic response. Journal of Structural Engineering, ASCE 124(11): 1281-1289.

Benjamin JR. 1988. A criterion for determining exceedance of the operating basis earthquake. EPRI Report NP-5930, Electric Power Research Institute, Palo Alto, California.

CEN. 1994. Eurocode8, Design Provisions for Earthquake Resistance of Structure. ENV1998-1, Brussels.

China Ministry of Construction. 2001. Code for seismic design of buildings (GB50011-2001). China Architecture \& Building Press, Beijing.

Fajfar P, Vidic T, Fischinger M. 1990. A measure of earthquake motion capacity to damage medium-period structures. Soil Dynamics and Earthquake Engineering 9(5): 236-242.

Hao M, Xie LL, Xu LJ. 2005. Some considerations on the physical measure of seismic intensity. Acta Seismologica Sinica 27(2): 230-234.

Housner GW. 1952. Spectrum intensity of strong motion earthquakes. Proceedings of the Symposium on Earthquakes and Blast Effects on Structures, Earthquake Engineering Research Institute, California: 20-36.

Housner GW, Jennings PC. 1964. Generation of artificial earthquakes. Journal of Engineering Mechanics Division, ASCE 90(EM1): 113-150.

Housner GW. 1975. Measures of severity of earthquake ground shaking. Proceedings of the U.S. National Conference on Earthquake Engineering, Earthquake Engineering Research Institute, Ann Arbor, MI.

Housner GW, Jennings PC. 1977. The capacity of extreme earthquake motions to damage structures. Structural and Geotechnical Mechanics, A volume honoring NM Newmark, Prentice Hall: 102-116.

Japanese Ministry of Construction. 2000. Japanese Building Code.

Kramer SL. 1996. Geotechnical Earthquake Engineering. Prentice-Hall, New Jersey.

Liu HS. 1958. Seismic forces on structures. Chinese Journal of Civil Engineering 5(2): 86-106.

Nau JM, Hall WJ. 1982. An evaluation of scaling methods for earthquake response spectra. 
Structural Research Series No. 499, Department of Civil Engineering, University of Illinois, Urbana, IL.

Nau JM, Hall WJ. 1984. Scaling methods for earthquake response spectra. Journal of Structural Engineering, ASCE 110(7): 1533-1548.

Nuttli OW. 1979. The relation of sustained maximum ground acceleration and velocity to earthquake intensity and magnitude. Miscellaneous Paper S-73-1, Report 16, U.S. Army Corps of Engineers, Waterways Experiment Station, Vicksburg, Mississippi.

Pacific Earthquake Engineering Research Center. 2005. PEER strong motion database [DB/OL]. California, Berkley. http://peer.berkeley.edu/smcat/index.html [September 2005].

Park YJ, Ang AHS, Wen YK. 1985. Seismic damage analysis of reinforced concrete buildings. Journal of Structural Engineering, ASCE 111(4): 740-757.

Riddell R, Garcia EJ. 2001. Hysteretic energy spectrum and damage control. Earthquake Engineering and Structural Dynamics 30(12): 1791-1816.

Riddell R. 2007. On ground motion intensity indices. Earthquake Spectra 23(1): 147-173.

Sarma SK, Yang KS. 1987. An evaluation of strong motion records and a new parameter A95. Earthquake Engineering and Structural Dynamics 15(1): 119-132.

Sucuoglu H, Nurtug A. 1995. Earthquake ground motion characteristics and seismic energy dissipation. Earthquake Engineering and Structural Dynamics 24(9): 1195-1213.

Trifunac MD, Brady AG. 1975. A study on the duration of strong earthquake ground motion. Bulletin of the Seismological Society of America 65(3): 581-626.

Vamvatsikos D, Cornell CA. 2002. Incremental dynamic analysis. Earthquake Engineering and Structural Dynamics 31(3): 491-514.

Ye LP, Lu XZ, Ma QL, Wang XL, Miao ZW. 2006. Nonlinear analytical models, methods and examples for concrete structures subject to earthquake loading. Engineering Mechanics 23(2): 131-140. 


\section{Notation}

The following symbols are used in this paper:

$a_{\max }=$ peak ground acceleration;

$a_{\mathrm{rs}}=$ root-square acceleration of Nau and Hall index;

$a_{\mathrm{rms}}=$ root-mean-square acceleration;

$d_{\max }=$ peak ground displacement;

$d_{\mathrm{rs}}=$ root-square displacement of Nau and Hall index;

$d_{\mathrm{rms}}=$ root-mean-square displacement;

$E_{a}, E_{\mathrm{v}}, E_{\mathrm{d}}=$ square acceleration, velocity and displacement of Nau and Hall index, respectively;

$E_{\mathrm{e}, \max }=$ maximum strain energy in a seismic elastic system;

$E_{\mathrm{H}}=$ hysteresis energy;

$E_{\mathrm{I}}=$ input energy;

$g=$ gravity acceleration;

$I=$ intensity index;

$I_{\mathrm{A}}=$ Arias intensity;

$I_{a}, I_{\mathrm{v}}, I_{\mathrm{d}}=$ Riddell's three-parameter intensity used in acceleration region, velocity region and displacement region, respectively;

$I_{\mathrm{c}}=$ characteristic intensity (Park-Ang intensity);

$I_{\mathrm{F}}=$ Fajfar intensity;

$m=$ mass of a seismic elastic system;

$P=$ Housner intensity;

$P_{a}, P_{\mathrm{v}}, P_{\mathrm{d}}=$ mean-square acceleration, velocity and displacement, respectively;

$P_{\mathrm{D}}=$ modified Arias intensity;

$R=$ strength reduction factor;

$S_{a}, S_{\mathrm{v}}, S_{\mathrm{d}}=$ spectral acceleration, pseudo-spectral velocity and spectral displacement, respectively; $S_{\mathrm{a}}\left(T_{1}\right)=$ first-mode spectral acceleration;

$S_{\mathrm{I}}=$ Housner spectrum intensity;

$T=$ structural period;

$t_{95}, t_{5}=$ the times where $95 \%$ and $5 \%$ of the Arias intensity is reached, respectively;

$t_{1}, t_{2}=$ the limits of the strong portion of ground motion;

$t_{\mathrm{D}}=$ significant duration of ground motion;

$t_{\mathrm{f}}=$ total duration of ground motion;

$v_{0}=$ number of zero-crossings per unit time on the accelerogram;

$v_{\max }=$ peak ground velocity;

$v_{\mathrm{rs}}=$ root-square velocity of Nau and Hall index;

$v_{\mathrm{rms}}=$ root-mean-square velocity;

$\ddot{x}(t), \dot{x}(t), x(t)=$ time history of ground acceleration, velocity and displacement, respectively;

$\rho=$ correlation coefficient;

$\xi=$ damping ratio of a structure. 
Table 1. Intensity indices.

\begin{tabular}{|c|c|c|c|c|}
\hline No. & \multicolumn{2}{|c|}{ Description of intensity } & Symbol & Expression \\
\hline 1 & \multicolumn{2}{|c|}{ Peak Ground Acceleration } & PGA & $a_{\max }$ \\
\hline 2 & \multicolumn{2}{|c|}{ Peak Ground Velocity } & PGV & $v_{\max }$ \\
\hline 3 & \multicolumn{2}{|c|}{ Peak Ground Displacement } & PGD & $d_{\max }$ \\
\hline 4 & \multicolumn{2}{|c|}{ Peak Spectrum Acceleration } & PSA & $\max \left(S_{\mathrm{a}}\right)$ \\
\hline 5 & \multicolumn{2}{|c|}{ Peak Spectrum Velocity } & PSV & $\max \left(S_{\mathrm{v}}\right)$ \\
\hline 6 & \multicolumn{2}{|c|}{ Peak Spectrum Displacement } & PSD & $\max \left(S_{\mathrm{d}}\right)$ \\
\hline 7 & \multicolumn{2}{|l|}{ Ratio of PGV/PGA } & $\mathrm{PGV} / \mathrm{PGA}$ & $v_{\max } / a_{\max }$ \\
\hline 8 & \multicolumn{2}{|c|}{ Housner Spectrum Intensity } & $S_{\mathrm{I}}$ & Equation (2) \\
\hline 9 & \multicolumn{2}{|l|}{ Arias Intensity } & $I_{\mathrm{A}}$ & Equation (3) \\
\hline 10 & \multicolumn{2}{|c|}{ Modified Arias Intensity } & $I_{\mathrm{A}, \mathrm{m}}$ & Equation (5) \\
\hline 11 & \multirow{7}{*}{ Housner Intensity } & Mean-square Acceleration & $P_{a}$ & Equation (7) \\
\hline 12 & & Mean-square Velocity & $P_{\mathrm{v}}$ & Equation (8) \\
\hline 13 & & Mean-square Displacement & $P_{\mathrm{d}}$ & Equation (9) \\
\hline 14 & & Root-mean-square Acceleration & $a_{\mathrm{rms}}$ & Equation (10) \\
\hline 15 & & Root-mean-square Velocity & $v_{\text {rms }}$ & Equation (10) \\
\hline 16 & & Root-mean-square Displacement & $d_{\mathrm{rms}}$ & Equation (10) \\
\hline 17 & & Square Acceleration & $E_{a}$ & Equation (11) \\
\hline 18 & Nau and Hall & Square Velocity & $E_{\mathrm{v}}$ & Equation (11) \\
\hline 19 & \multirow{4}{*}{ Indices } & Square Displacement & $E_{\mathrm{d}}$ & Equation (11) \\
\hline 20 & & Root-square Acceleration & $a_{\mathrm{rs}}$ & Equation (12) \\
\hline 21 & & Root-square Velocity & $v_{\mathrm{rs}}$ & Equation (12) \\
\hline 22 & & Root-square Displacement & $d_{\mathrm{rs}}$ & Equation (12) \\
\hline 23 & \multicolumn{2}{|l|}{ Park-Ang Intensity } & $I_{\mathrm{c}}$ & Equation (13) \\
\hline 24 & \multirow{2}{*}{\multicolumn{2}{|c|}{ Fajfar Intensity }} & $I_{\mathrm{F}}$ & Equation (14) \\
\hline 25 & & & $I_{\mathrm{d}}$ & Equation (16-a) \\
\hline 26 & \multirow{2}{*}{\multicolumn{2}{|c|}{ Riddell Three-parameter Intensity }} & $I_{\mathrm{V}}$ & Equation (16-b) \\
\hline 27 & & & $I_{a}$ & Equation (16-c) \\
\hline 28 & \multicolumn{2}{|c|}{ "First-mode" Spectral Acceleration } & $S_{\mathrm{a}}\left(T_{1}\right)$ & $S_{\mathrm{a}}\left(T_{1}, \xi\right)$ \\
\hline 29 & \multicolumn{2}{|c|}{ Cumulative Absolute Velocity } & CAV & Equation (17) \\
\hline 30 & \multicolumn{2}{|c|}{ Effective Design Acceleration } & EDA & - \\
\hline
\end{tabular}


Table 2. Sixty earthquake records (between 1961-1999) used in the study.

\begin{tabular}{|c|c|c|c|c|c|}
\hline Record ID & Record Station & $\begin{array}{c}\text { PGA } \\
(\mathrm{g})\end{array}$ & $\begin{array}{l}\mathrm{PGV} \\
(\mathrm{cm} / \mathrm{s})\end{array}$ & $\begin{array}{l}\text { PGD } \\
(\mathrm{cm})\end{array}$ & $\begin{array}{l}t_{\mathrm{D}} \\
(\mathrm{s})\end{array}$ \\
\hline U.S. Imperial Valley $16 / 10 / 79$ & 5169 Westmorland Fire Sta & 0.089 & 4.67 & 0.61 & 19.11 \\
\hline U.S. Big Bear 28/06/92 & 23542 San Bernardino-E\&Hospitality & 0.101 & 11.9 & 3.35 & 13.40 \\
\hline U.S. Loma Prieta 18/10/89 & 58471 Berkeley LBL & 0.117 & 20.85 & 4.42 & 23.61 \\
\hline U.S. Borrego Mtn 09/04/68 & 117 El Centro Array \#9 & 0.130 & 26.3 & 12.18 & 7.98 \\
\hline U.S. Anza(Horse Cany) 25/02/80 & 5044 Anza - Pinyon Flat & 0.131 & 5.1 & 0.49 & 25.57 \\
\hline U.S. Coyote Lake 06/08/79 & 47379 Gilroy Array \#1 & 0.132 & 8.3 & 1.52 & 1.83 \\
\hline U.S. Hollister 28/11/74 & 47379 Gilroy Array \#1 & 0.132 & 4.0 & 0.17 & 5.76 \\
\hline U.S. San Fernando 09/02/71 & 127 Lake Hughes \#9 & 0.157 & 4.5 & 1.28 & 2.42 \\
\hline U.S. Superstitn Hills(B) 24/11/87 & 5062 Salton Sea Wildlife Refuge & 0.167 & 18.3 & 4.3 & 9.99 \\
\hline U.S. Northridge 17/01/94 & 90011 Montebello-Bluff Rd. & 0.179 & 9.4 & 1.48 & 13.00 \\
\hline U.S. Hollister 09/04/61 & 1028 Hollister City Hall & 0.196 & 12.4 & 4.29 & 10.62 \\
\hline Taiwan Chi-Chi 20/09/99 & ILA067 & 0.200 & 11.84 & 7.72 & 17.16 \\
\hline U.S. Chalfant Valley 21/07/86 & 54100 Benton & 0.210 & 13.54 & 2.87 & 19.11 \\
\hline U.S. Westmorland 26/04/81 & 5062 Salton Sea Wildlife Ref. & 0.214 & 4.8 & 1.08 & 16.69 \\
\hline U.S. Loma Prieta 18/10/89 & 1002 APEEL 2-Redwood City & 0.220 & 34.3 & 6.87 & 6.17 \\
\hline Japan Kobe 16/01/95 & 0 Shin-Osaka & 0.243 & 37.8 & 8.54 & 11.79 \\
\hline Turkey Kocaeli 17/08/99 & Ambarli & 0.249 & 40.0 & 30.08 & 10.31 \\
\hline U.S. Whittier Narrows 01/10/87 & 90009 N Hollywood-Coldwater Can & 0.250 & 14.3 & 1.11 & 36.62 \\
\hline Japan Kobe 16/01/95 & 0 Kakogawa & 0.251 & 18.7 & 5.83 & 10.21 \\
\hline U.S. Livermore $27 / 01 / 80$ & 57T02 Livermore-Morgan Terr Park & 0.252 & 9.8 & 1.3 & 13.16 \\
\hline U.S. Loma Prieta 18/10/89 & 58235 Saratoga W Valley Coll. & 0.255 & 42.4 & 19.55 & 2.43 \\
\hline U.S. Livermore 27/01/80 & 57T01 Livermore-Fagundas Ranch & 0.258 & 9.6 & 0.55 & 11.11 \\
\hline Italy Friuli 15/09/76 & 8014 Forgaria Cornino & 0.260 & 9.3 & 1.07 & 3.06 \\
\hline Turkey Kocaeli 17/08/99 & Yarimca & 0.268 & 65.7 & 57.01 & 4.44 \\
\hline U.S. San Fernando 09/02/71 & 24278 Castaic - Old Ridge Route & 0.268 & 25.9 & 4.67 & 15.34 \\
\hline U.S. Northridge 17/01/94 & 90009 N. Hollywood Coldwater Can & 0.271 & 22.2 & 11.69 & 15.37 \\
\hline Japan Kobe16/01/95 & 0 Takatori & 0.272 & 16.0 & 4.47 & 16.42 \\
\hline U.S. Parkfield 28/06/66 & 1438 Temblor pre-1969 & 0.272 & 15.0 & 3.4 & 13.53 \\
\hline U.S. Northridge 17/01/94 & 90016 LA N Faring Rd & 0.273 & 15.8 & 3.29 & 5.62 \\
\hline U.S. Parkfield 28/06/66 & 1015 Cholame \#8 & 0.273 & 11.3 & 3.2 & 10.80 \\
\hline U.S. Landers 28/06/92 & 22170 Joshua Tree & 0.274 & 27.5 & 9.82 & 8.78 \\
\hline U.S. Loma Prieta 18/10/89 & 1002 APEEL 2 Redwood City & 0.274 & 53.6 & 12.68 & 8.40 \\
\hline U.S. Loma Prieta 18/10/89 & 1601 Palo Alto SLAC Lab & 0.278 & 29.3 & 9.72 & 11.57 \\
\hline U.S. Morgan Hill 24/04/84 & 57383 Gilroy Array \#6 & 0.292 & 36.7 & 6.12 & 26.02 \\
\hline U.S. Whittier Narrows 01/10/87 & 90079 Downey Birchdale & 0.299 & 37.8 & 4.95 & 6.47 \\
\hline Taiwan Chi-Chi 20/09/99 & CHY041 & 0.302 & 20.4 & 8.62 & 3.07 \\
\hline U.S. Whittier Narrows 01/10/87 & 90019 San Gabriel E Grand Av & 0.304 & 23.0 & 3.34 & 30.17 \\
\hline Italy Friuli 06/05/76 & 2000 Tolmezzo & 0.310 & 30.8 & 5.08 & 4.99 \\
\hline U.S. Coyote Lake 08/06/79 & 1705 Gilroy Array \#2 & 0.340 & 24.87 & 5.82 & 4.93 \\
\hline Italy Friuli 06/05/76 & 2000 Tolmezzo & 0.350 & 22.0 & 4.11 & 4.36 \\
\hline Italy Irpinia 23/11/80 & Sturno & 0.360 & 52.7 & 33.1 & 4.24 \\
\hline U.S. Loma Prieta 18/10/89 & 47381Gilroy Array \#3 & 0.370 & 44.65 & 19.33 & 15.48 \\
\hline U.S. Cape Mendocino 25/04/92 & 1806 Rio Dell Overpass Ff. & 0.385 & 43.8 & 21.64 & 11.25 \\
\hline U.S. Loma Prieta 18/10/89 & 58135 UCSC Lick Observatory & 0.390 & 17.53 & 5.03 & 14.89 \\
\hline U.S. Chalfant Valley 21/07/86 & 54428 Zack Brothers Ranch & 0.4 & 44.52 & 8.59 & 9.67 \\
\hline U.S. Coalinga 22/07/83 & 1162 Pleasant Valley P.P. - FF & 0.41 & 18.9 & 5.63 & 8.13 \\
\hline U.S. Landers 28/06/92 & 23 Coolwater & 0.42 & 42.34 & 13.82 & 5.49 \\
\hline
\end{tabular}




\begin{tabular}{llllll} 
U.S. Coyote Lake 06/08/79 & 1705 Gilroy Array \#6 & 0.43 & 49.22 & 7.67 & 8.22 \\
U.S. Loma Prieta 18/10/89 & 47379 Gilroy Array \#1 & 0.473 & 33.9 & 8.03 & 3.23 \\
U.S. Imperial Valley 15/10/79 & 2316 El Centro Array \#4 & 0.49 & 37.4 & 20.1 & 3.65 \\
Turkey Duzce 12/11/99 & Duzce & 0.54 & 83.5 & 51.6 & 6.69 \\
U.S. Cape Mendocino 25/04/92 & 1806 Petrolia & 0.59 & 48.1 & 21.92 & 10.78 \\
Japan Kobe 16/01/95 & 2046, Kjm, 090 & 0.6 & 74.32 & 19.9 & 17.57 \\
U.S. N. Palm Springs 08/07/86 & 5072 Whitewater Trout Farm & 0.612 & 31.5 & 4.58 & 9.52 \\
Mexico Victoria 09/06/80 & 6604 Cerro Prieto & 0.621 & 31.6 & 13.2 & 3.38 \\
U.S. Cape Mendocino 25/04/92 & 1806 Petrolia & 0.66 & 89.66 & 28.98 & 8.76 \\
U.S. USSR Gazli 17/05/76 & 9201 Karakyr & 0.72 & 71.55 & 23.7 & 15.96 \\
U.S. Landers 28/06/92 & 24 Lucerne & 0.785 & 31.9 & 16.42 & 6.79 \\
Japan Kobe 16/01/95 & 2046, Kjm, 000 & 0.82 & 81.28 & 17.68 & 13.53 \\
Turkey Duzce 12/11/99 & Bolu & 0.822 & 62.1 & 13.55 & 8.32 \\
\hline
\end{tabular}




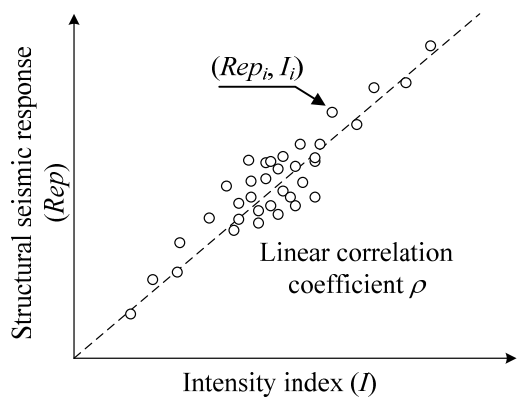

Figure 1. Correlation between intensity indices and structural seismic responses 


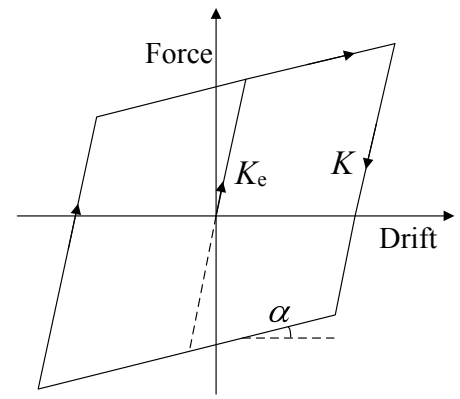

Figure 2. Hysteresis model 

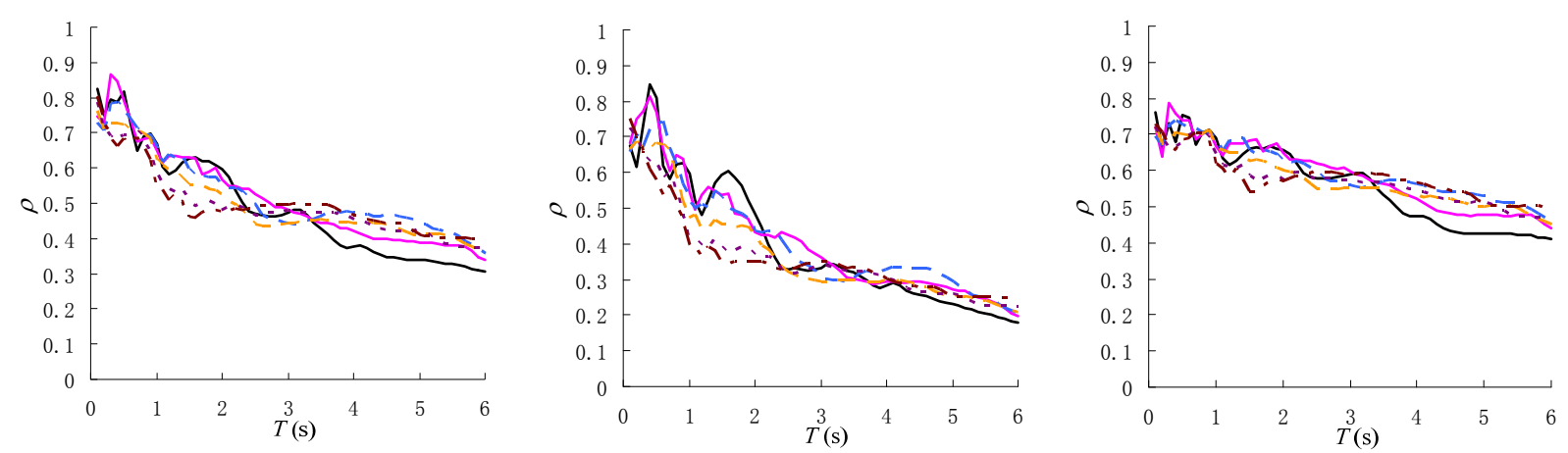

Peak Ground Acceleration (PGA)

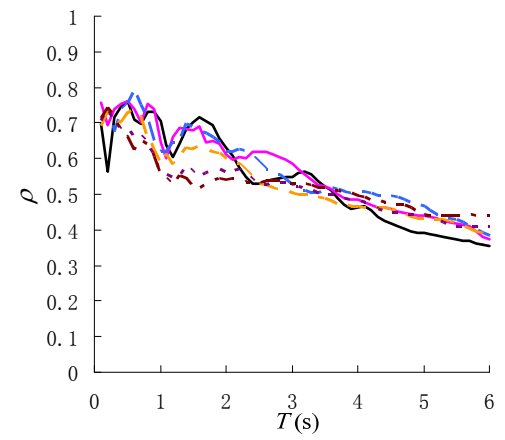

Arias Intensity $\left(I_{\mathrm{A}}\right)$
Housner Mean-square Acceleration Riddell Three-parameter Intensity $\left(P_{a}\right)$

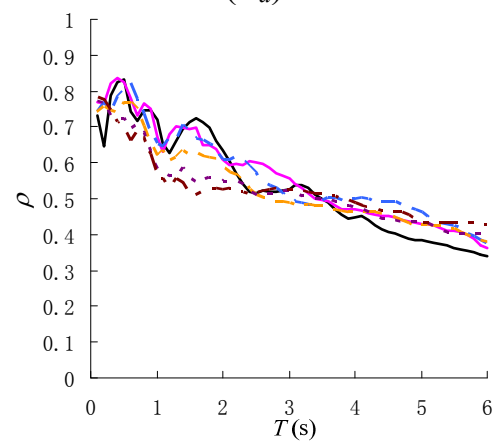

Park-Ang Intensity $\left(I_{\mathrm{c}}\right)$
$\left(I_{a}\right)$

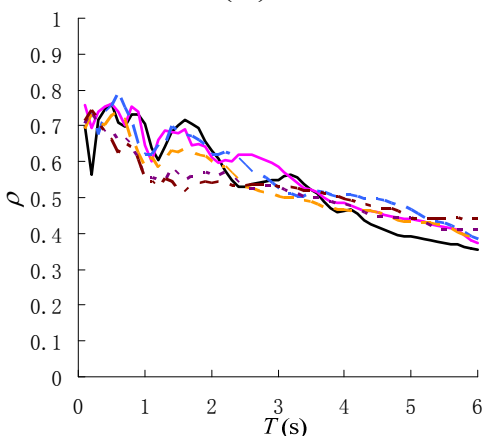

Nau \& Hall Square Acceleration

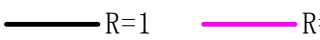

$\mathrm{R}=2 \quad-\mathrm{R}=3 \quad-\mathrm{R}=4$

$\left(E_{a}\right)$

(a) Group 1

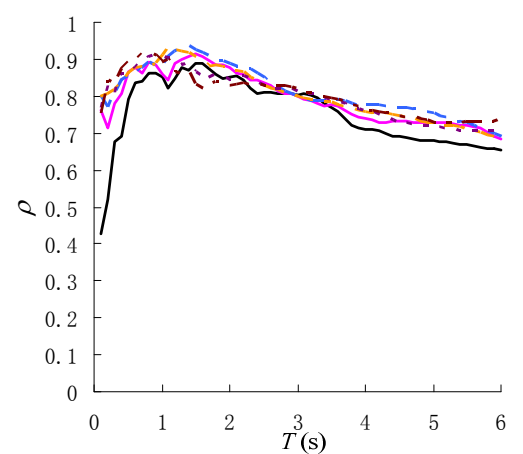

Peak Ground Velocity (PGV)

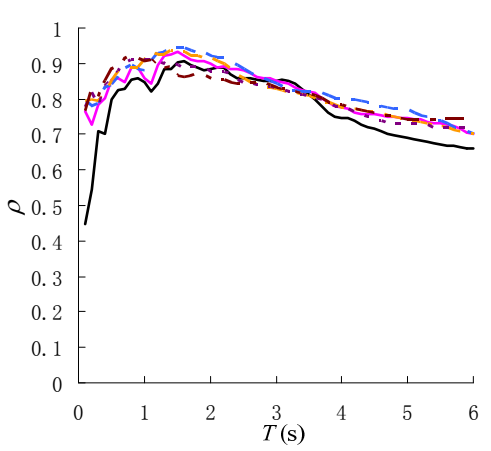

Housner Spectrum Intensity $\left(S_{\mathrm{I}}\right)$

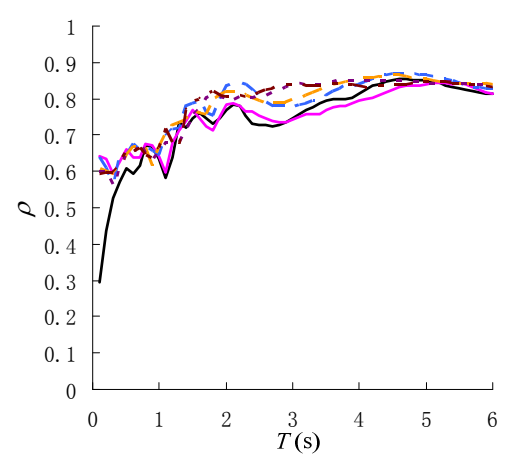

Housner Mean-square Velocity $\left(P_{\mathrm{v}}\right)$

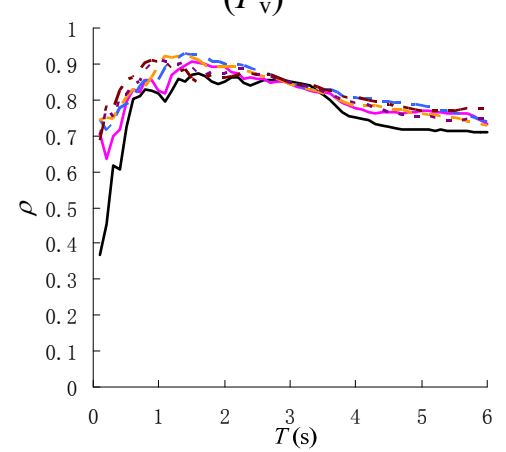

Fajfar Intensity $\left(I_{\mathrm{F}}\right)$

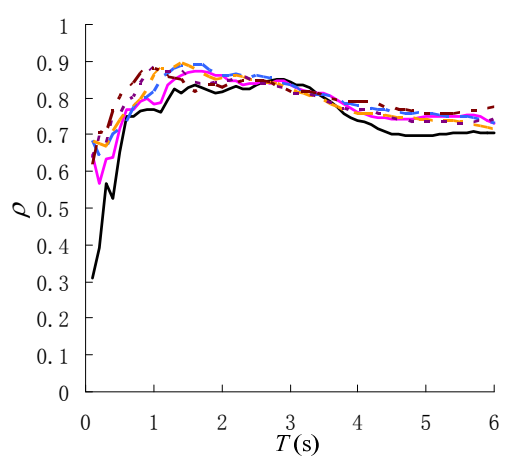

Riddell Three-parameter Intensity $\left(I_{\mathrm{v}}\right)$

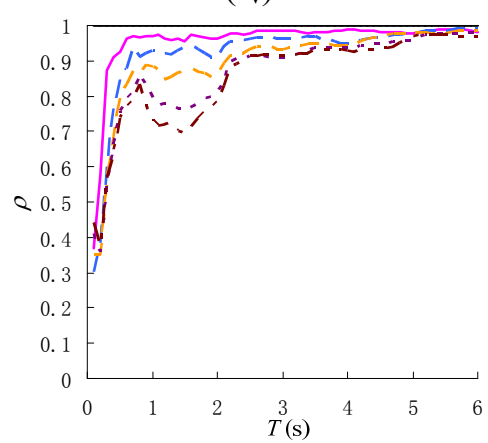

"First-mode" Spectral Acceleration $\left(S_{a}\left(T_{1}\right)\right)$

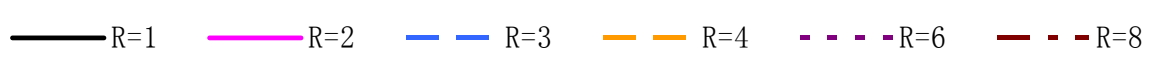

(b) Group 2 


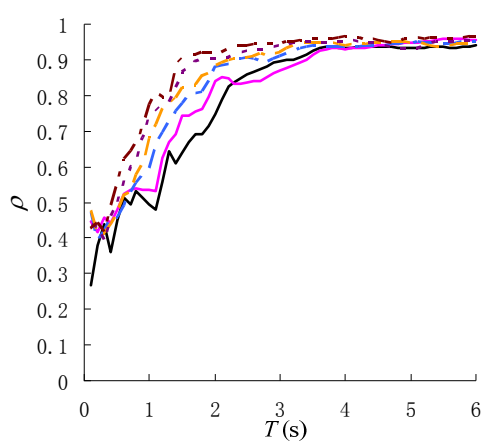

Peak Ground Displacement (PGD)

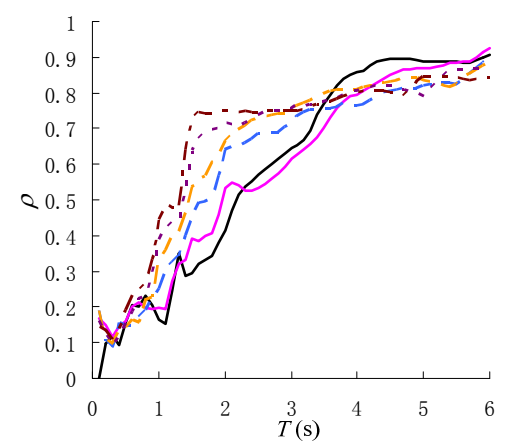

Nau \& Hall Square Displacement Nau \& Hall Square Velocity $\left(E_{v}\right)$ $\left(E_{\mathrm{d}}\right)$

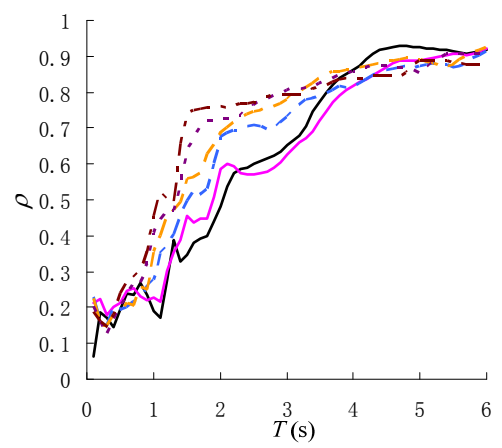

Housner Mean-square Displacement $\left(P_{\mathrm{d}}\right)$

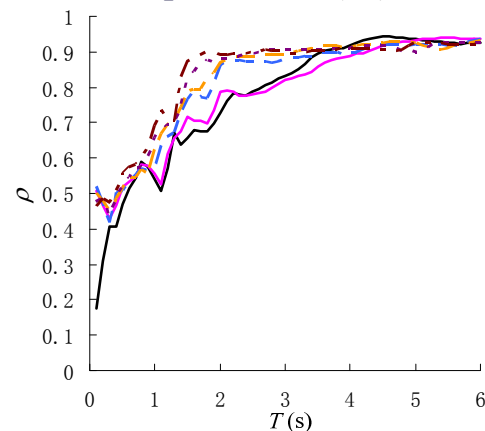

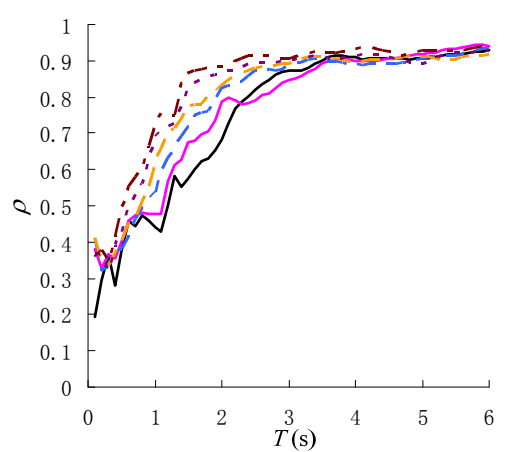

Riddell Three-parameter Intensity $\left(I_{\mathrm{d}}\right)$

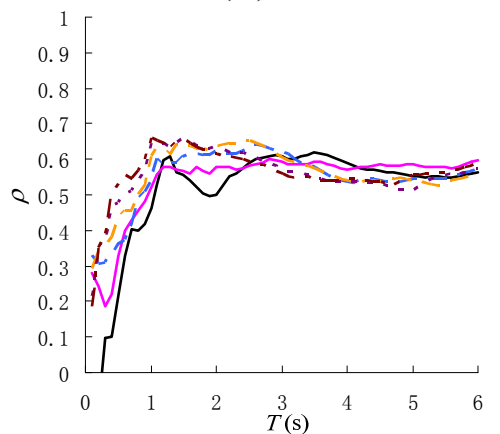

Ratio of PGV/PGA (PGV/PGA)

$\longrightarrow \mathrm{R}=1 \longrightarrow \mathrm{R}=2-\mathrm{R}=3 \quad-\mathrm{R}=4 \quad--\mathrm{R}=6 \quad-\quad-\mathrm{R}=8$

(c) Group 3

Figure 3. $\rho-T$ relationships for $S_{\mathrm{d}}$ under various $I$ and $R$. 


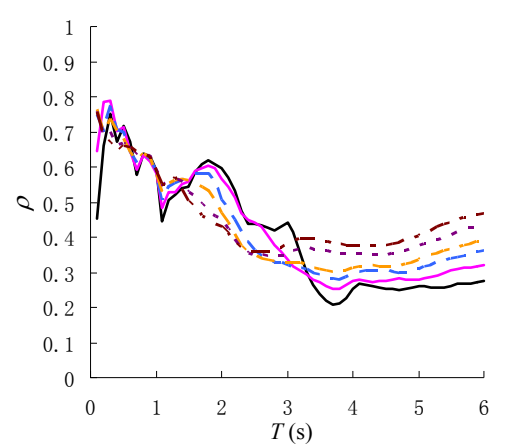

Peak Ground Acceleration (PGA)

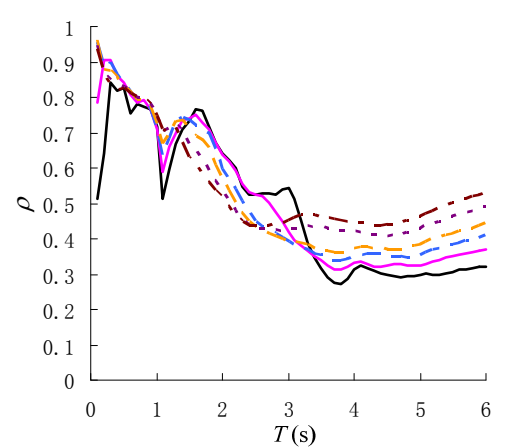

Arias Intensity $\left(\mathrm{I}_{\mathrm{A}}\right)$

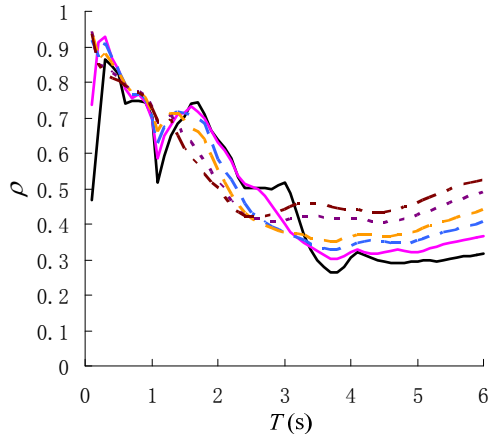

Park-Ang Intensity $\left(I_{\mathrm{c}}\right)$<smiles>C[Te][P]</smiles>

(a) Group 1

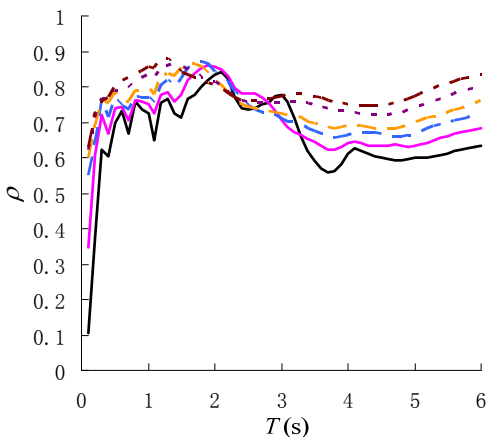

Peak Ground Velocity (PGV)

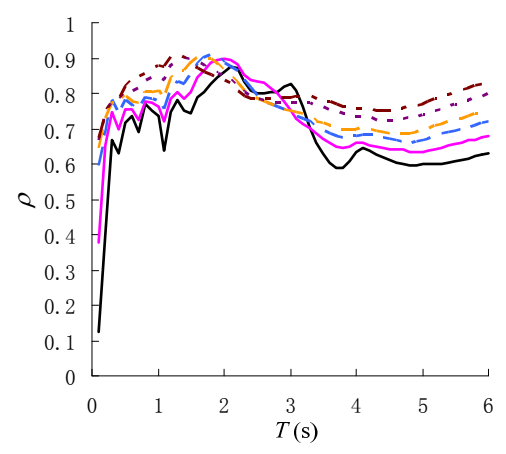

Housner Spectrum Intensity $\left(S_{\mathrm{I}}\right)$

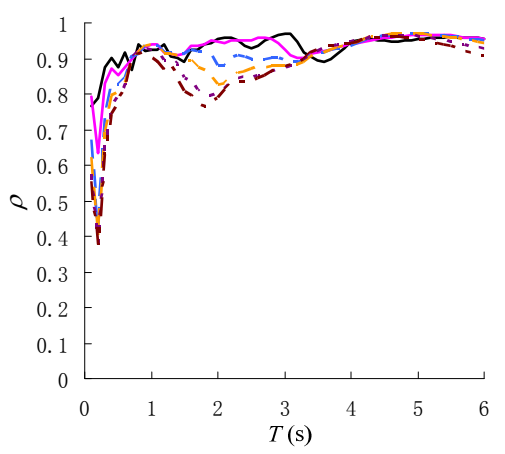

"First-mode" Spectral Acceleration $\left(S_{a}\left(T_{1}\right)\right)$

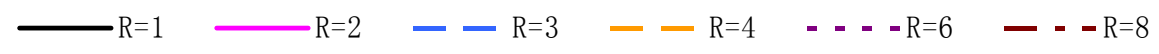

(b) Group 2

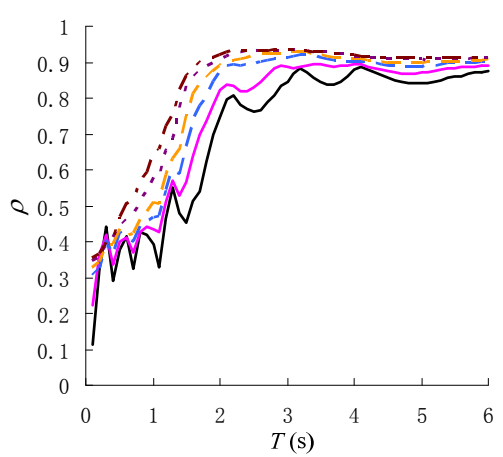

Peak Ground Displacement (PGD)

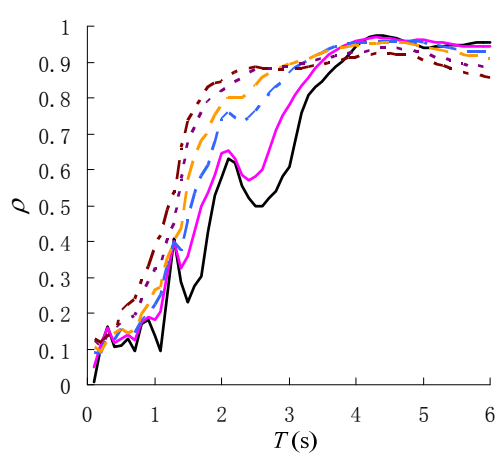

Housner Mean-square Displacement $\left(P_{\mathrm{d}}\right)$

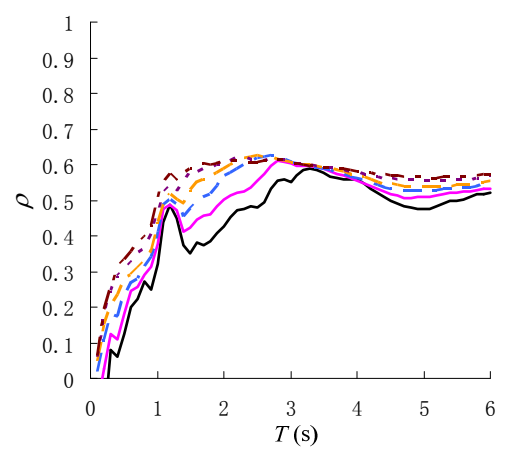

Ratio of PGV/PGA (PGV/PGA)

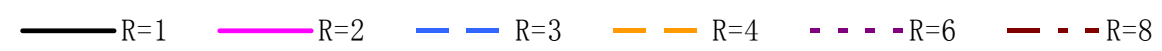

(c) Group 3

Figure 4. $\rho$-T relationships for $E_{\mathrm{I}}$ under various $I$ and $R$. 

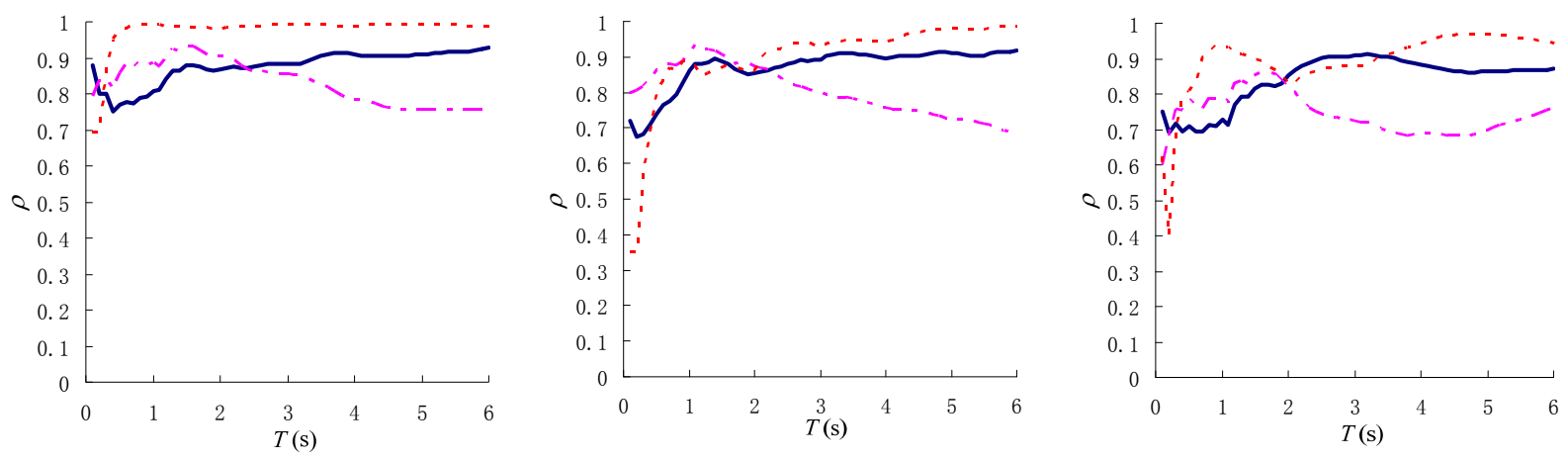

Riddell three parameter intensity index

PGV

$S_{a}\left(T_{1}\right)$

(a) $S_{a \mathrm{t}}$

(b) $S_{\mathrm{d}}$

(c) $E_{\mathrm{I}}$

Figure 5. Comparison between Riddell's three-parameter intensity index and, PGV and $\mathrm{S}_{a}\left(T_{1}\right)$. 


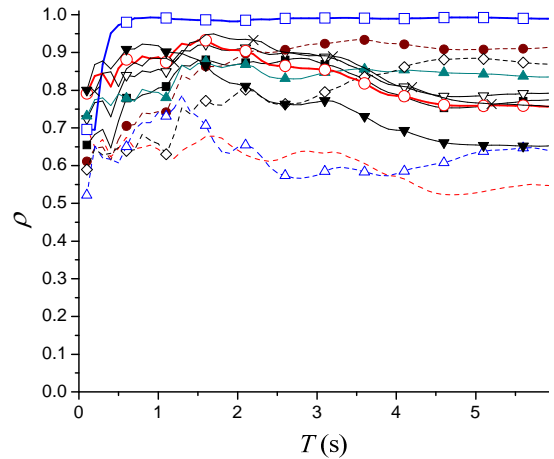

(a) $S_{\mathrm{a}}$

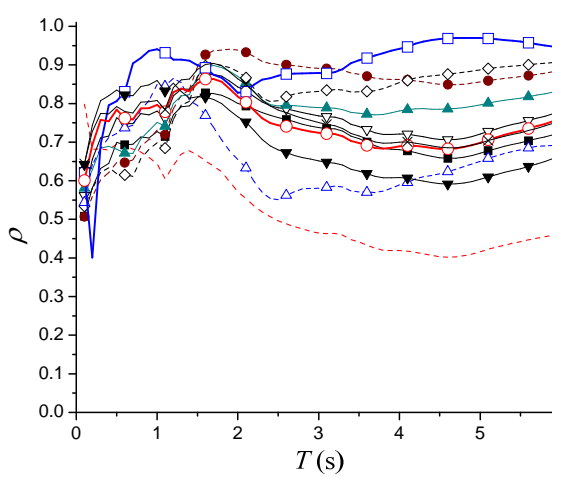

(c) $E_{\mathrm{I}}$

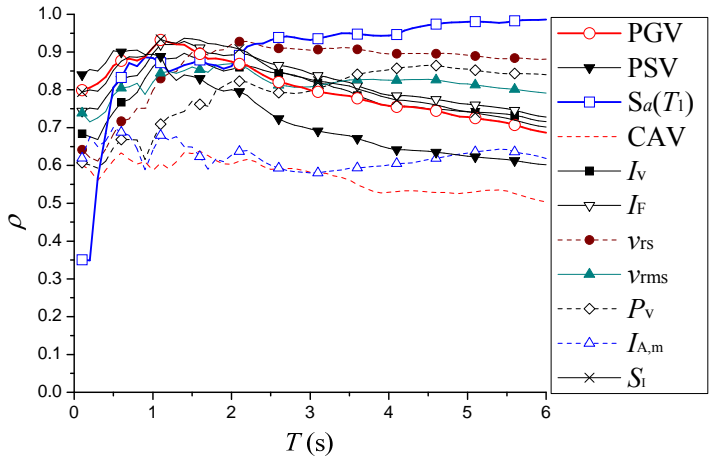

(b) $S_{\mathrm{d}}$

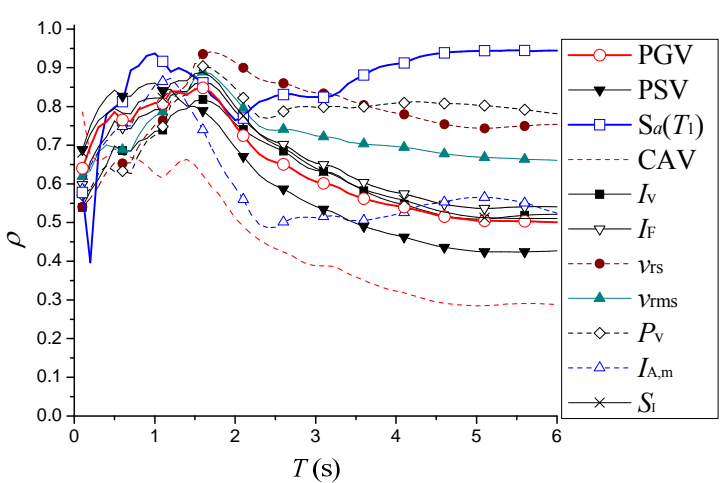

(d) $E_{\mathrm{H}}$

Figure 6. $\rho$ - $T$ relationships for maximum seismic responses under various $I$ in Group 2 (SDOF, $R=4$ ). 


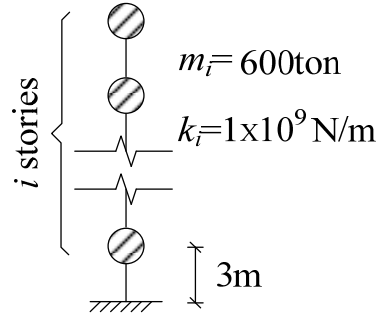

(a) The model

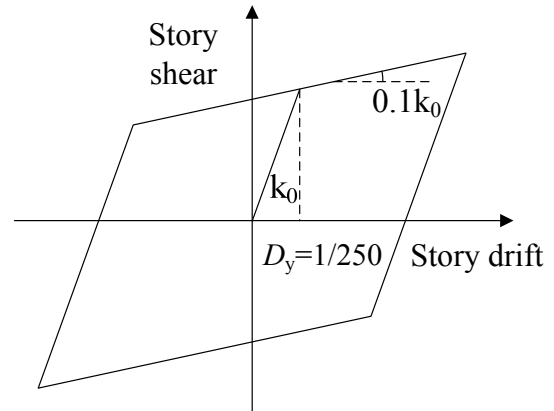

(b) Relationship between shear and drift

Figure 7. Lumped mass shear story model. 


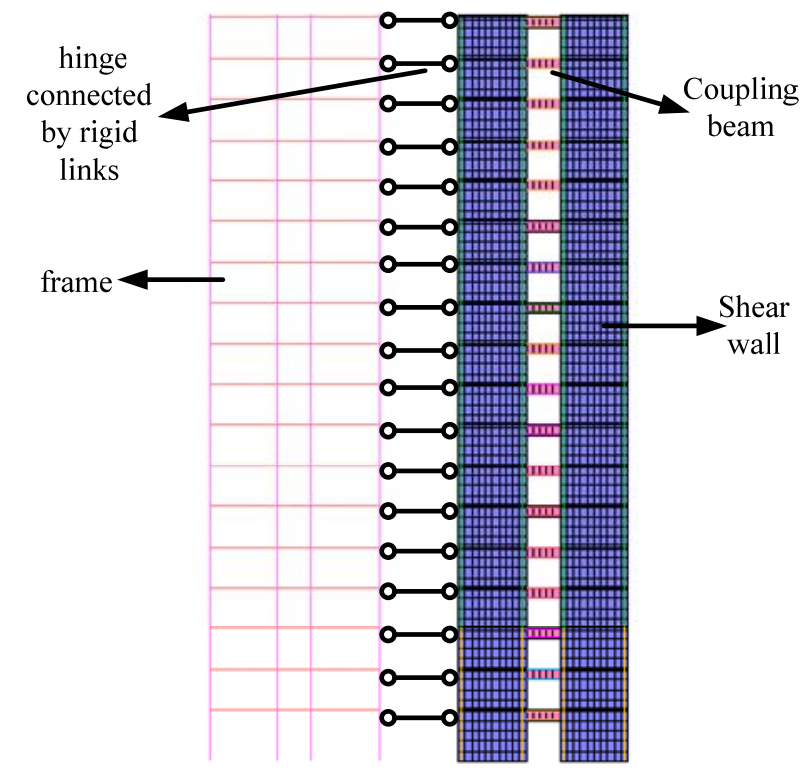

Figure 8. Planar frame shear-wall structure. 


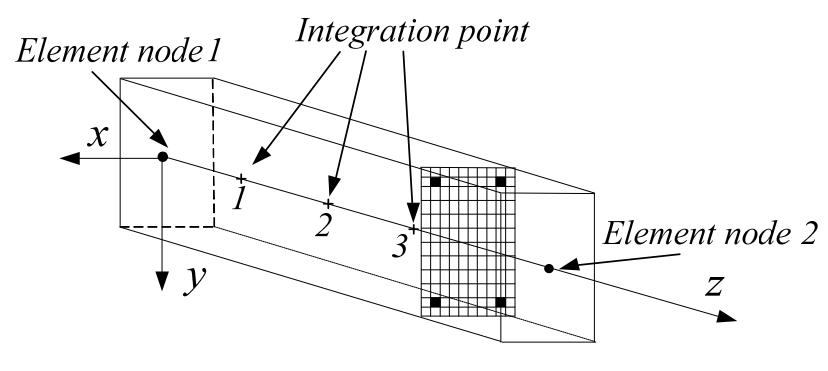

(a) Fiber-model element

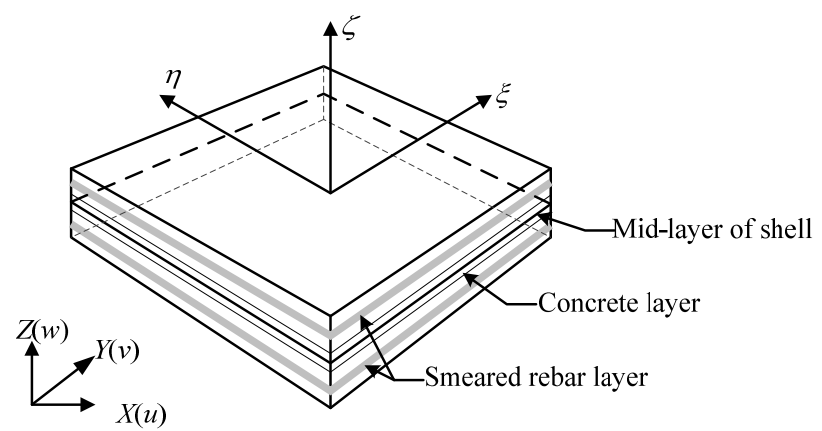

(b) Multi-layer shell element

Figure 9. Frame and shear wall modeling technique. 


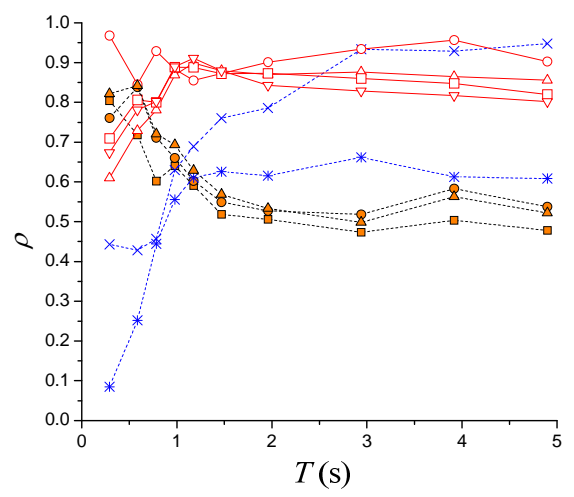

(a) Peak roof displacement

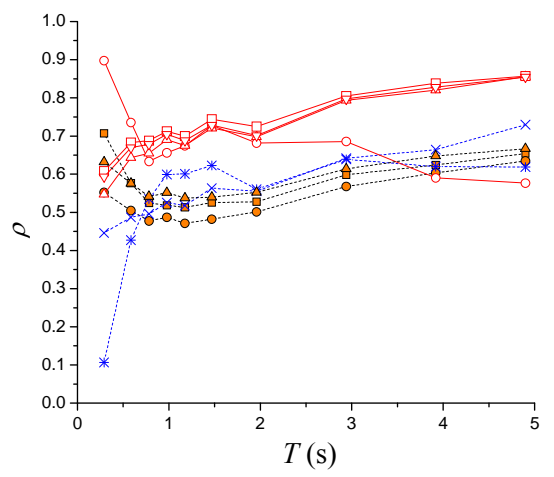

(c) Maximum base shear

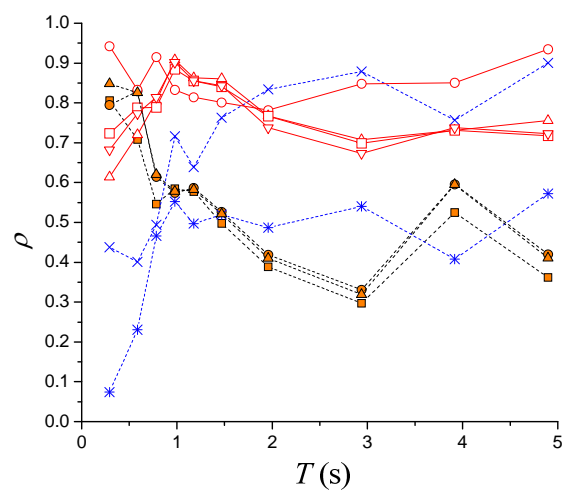

(b) Maximum story drift

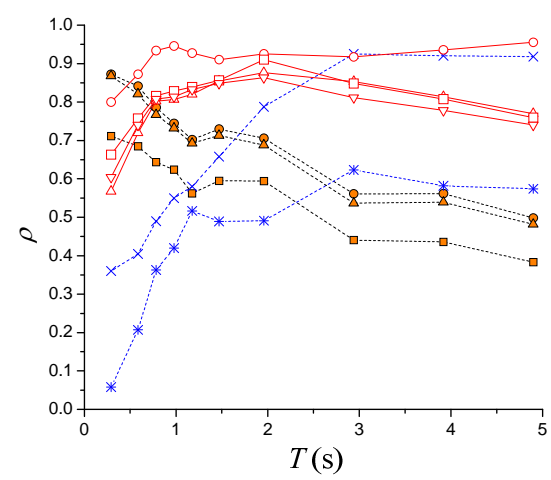

(d) Input energy

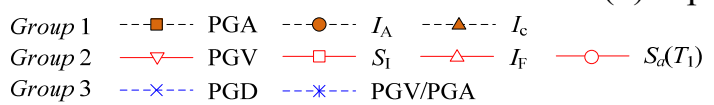

Figure 10. $\rho-T$ relationships for lumped mass MDOF systems. 


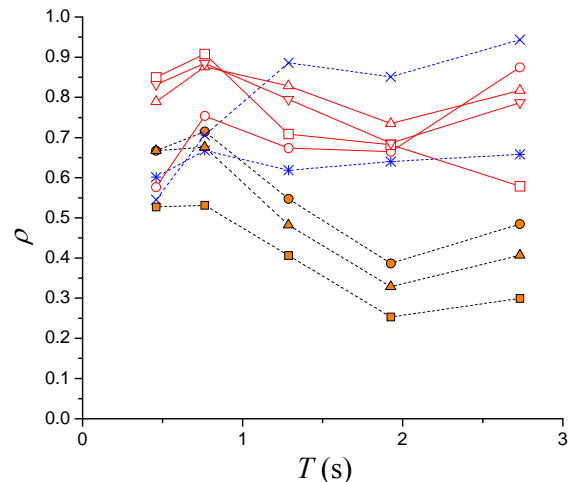

(a) Peak roof displacement

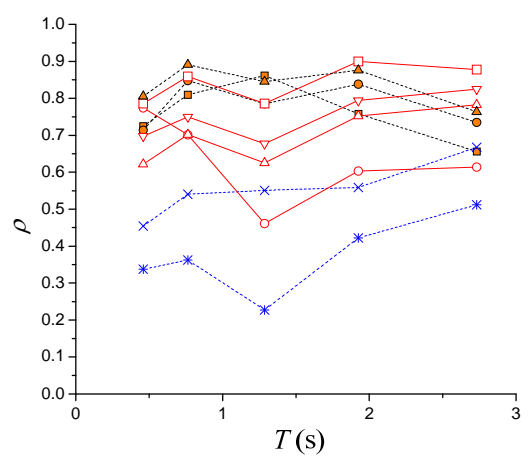

(c) Maximum base shear

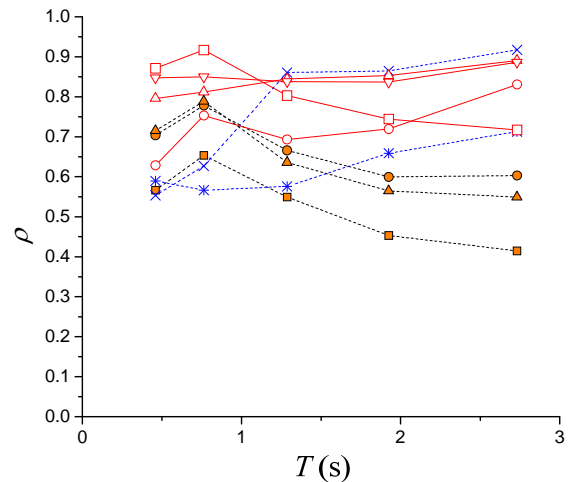

(b) Maximum story drift

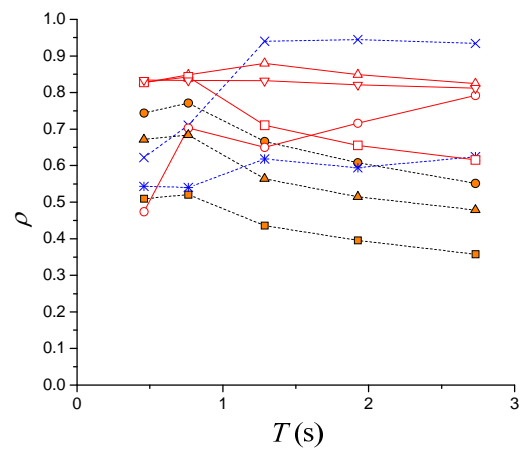

(d) Input energy

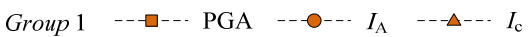

$$
\begin{aligned}
& \text { Group } 2 \longrightarrow \mathrm{PGV} \longrightarrow \square-S_{\mathrm{I}} \longrightarrow I_{\mathrm{F}} \longrightarrow S_{d}\left(T_{1}\right) \\
& \text { Group } 3 \text {---^--- PGD ---*--. PGV/PGA }
\end{aligned}
$$

Figure 11. $\rho$ - $T$ relationships for planar frame shear-wall structures. 